\title{
Empowerment as a Mediator between Education and Reproductive Health Care in Egypt: The Impact of Poverty and Residence
}

\author{
Rasha Aly Mohamed Aly \\ Department of Business Administration and Management Information System, Cairo Higher Institute for Engineering and \\ Computer Sciences \& Management, New Cairo, Egypt \\ Email: ra.elsakka@gmail.com
}

How to cite this paper: Aly, R. A. M. (2021). Empowerment as a Mediator between Education and Reproductive Health Care in Egypt: The Impact of Poverty and Residence. Open Journal of Social Sciences, 9, 58-76.

https://doi.org/10.4236/jss.2021.93005

Received: February 9, 2021

Accepted: March 7, 2021

Published: March 10, 2021

Copyright $\odot 2021$ by author(s) and Scientific Research Publishing Inc. This work is licensed under the Creative Commons Attribution International License (CC BY 4.0).

http://creativecommons.org/licenses/by/4.0/

\begin{abstract}
Introduction: Since women's access to the required reproductive health care reduces maternal and foetal deaths and postpartum complications for both, this study examined the role of poverty and residence on the model where empowerment played a mediating role between education and women's access to reproductive health care. Methods: The study used the Multiple-Group Path Analysis based on the 2014 Egypt's Demographic Health Survey. Results: Women's Empowerment acts as a partial mediator between their education and receiving reproductive health care, while it acts as a full mediator between the husband's education and the woman's reception of that care. There are no significant differences among the categories of the residence and wealth models with regard to both the effect of education, of the woman and her husband, on empowerment and the effect of the latter on receiving health care. There is a significant difference among the categories of the wealth model regarding the effect of women's education on receiving health care, whereas this difference does not exist among the residence model categories. Conclusion: The effect of both women's education and empowerment on receiving reproductive health care is higher among the poor and the rural dwellers, while the effect of the husbands' education on empowerment is weak among these categories. Therefore, a new societal culture must be created through educational curricula, female illiteracy and dropping out of education stages must be reduced, and poverty must be mitigated through an integrated system targeted for small projects and supported by all facilities.
\end{abstract}

\section{Keywords}

Education, Empowerment as a Mediator, Reproductive Health Care, Wealth Index, Residence, Poverty, Multiple-Group Path Analysis, Egypt 


\section{Introduction}

When women's development is a priority to her society, this entails that this society aims to achieve comprehensive development. The reason for such conception is that women have the upper hand in lighting every new-born's intellect, male or female, in the community who will later move the development wheel in various fields within that community. Since Egypt has 48.7 million women, improving their conditions will inevitably lead to the development of the country's conditions in various fields (WEF, 2020). However, women will not perform their multiple assigned roles to the fullest unless they acquire a high level of health and empowerment.

Moreover, motherhood, which starts with the creation of the foetus in the womb, occupies the most important role in the lives of most women in Egypt. Medical care the mother and the foetus at this stage is inevitable to protect them both against health risks during and after pregnancy (Rashad \& Sharaf, 2016). Preeclampsia and postpartum haemorrhage are still the main causes of maternal deaths in Egypt and the developing countries (Abbas, Amin, Ali, \& Salem, 2016; Tanya Nagahawatte \& Goldenberg, 2008; Zahran, Fadel, Ahmed, \& El-Gazzar, 2017). In addition, the value of the infant mortality rate in Egypt (15.4\% in 2018) still cannot be underestimated although it was reduced by $50 \%$ as compared to its value in 2000 (CAPMAS, 2020).

Women's empowerment has enormous effects on the health and quality of life of the family and then the society accordingly (Kiani, Simbar, Dolatian, \& Zayeri, 2018). Women's empowerment is the basis for population and development programs in Egypt (Ragab et al., 2016) and it is also one of the Millennium Development Goals (Alishah, Ganji, Mohammadpour, Kiani, \& Shahhosseini, 2019). Zaky, Armanious, \& Hussein (2019) pointed out that women's empowerment should be considered as an important indicator for using prenatal health care services in Egypt.

However, most women are still facing difficulties in their families and community lives (UNWomen, 2020) due to the sovereignty of the males in society (Ragab et al., 2016), who always perceive that the last word in most decisions should be the men's. They also see that the role of the woman in decision-making is limited to only giving her opinion. The percentages confirm those male perceptions when the following question is posed: "Who is supposed to make the final decision in the family?" $90 \%$ of the men and approximately $86 \%$ of the women said that it was the man who was responsible for making decisions (El Feki, Heilman, \& Barker, 2017).

Despite the proliferation of the organizations concerned with women's empowerment and gender equality around the world since 1994 (Activities, 2014) and in spite of Egypt's recent achievements and progress in many indicators, (Shawky, Rashad, \& Khadr, 2018) promoting gender equality and empowering women in all areas of life continue to prevail as difficult challenges facing Egypt (WEF, 2020). These difficulties persist as they aim to change the intellectual sys- 
tem of most men and women alike, especially with regards to how the husband and the wife in a family deal with each other. Those challenges are what the National Council for Women (NCW) has been working on with a strategy for 2030 (Ministry of Planning, 2018). Many of the researches that aimed at studying the Egyptian society indicated that education was one of the most important ways to modify the intellectual system and achieve women's empowerment (Aly, 2000; Samari, 2019).

In addition, education plays an important role in women's health, especially the reproductive health. Studies have shown that women's education is associated with the behaviors related to searching for maternal health and survival services (Ahmed, Creanga, Gillespie, \& Tsui, 2010; Ikeako, Onah, \& Iloabachie, 2006; Tawiah, 2011). Studies also pointed out that the educational levels of the wife and the husband in Egypt are important indicators for using the prenatal health care services (Zaky et al., 2019). Moreover, the education levels are related to maternal deaths, (Dapaah \& Nachinaab, 2019) and the lack of education impedes the access to adequate maternal and child health care (Activities, 2011).

Although education in Egypt is one of the items under the list of problems that need solutions, not only in terms of illiteracy rates in society but also in terms of improving the quality of the education system as a real challenge for this society (Ministry of Planning, 2018). Though the population growth in Egypt is considered as an obstacle to the education system, over the past few years, Egypt has managed to raise the rate of the official youth literacy from $85 \%$ in 2005 to $94 \%$ in 2017 . The country also reduced the number of children in primary school age who were not enrolled in schools by $50 \%$ over the last five years before 2019 after the sharp rise during the 2011 revolution (Roach, 2019). In addition, Egypt witnessed the education restructuring initiative starting from the kindergarten to the twelfth grade, which is known as Education 2.0 (EDU 2.0 program), which was announced in 2018 to be fully implemented by 2030 (Group, 2020).

At this point, a question arises: can education and empowerment overcome the impact of poverty and the environment surrounding women? Attaining a certain level of education and empowerment will ensure that women take the expected course of action in receiving the required health care.

Studies indicate that there are obvious significant differences in the percentages of women receiving reproductive health care among the different categories of the social and economic classes and the residence places of the mothers (Ragab et al., 2016). Residence, whether it is urban or rural, is one of the most important indicators of inadequate antenatal care (Tawiah, 2011). Poverty is a key hindrance to women's survival during pregnancy and the period surrounding it (Izugbara \& Ngilangwa, 2010). It is related to an increase in many medical and behavioral risk factors associated with preterm birth and other pregnancy outcomes. Most of the discrepancies in those outcomes occur between the poor women on one side and other women on the other side (Tanya Nagahawatte \& Goldenberg, 2008). Additionally, the differences in the use of maternity care in 
Egypt exist due to a lack of resources and what is associated with it within the poor society (Rashad \& Sharaf, 2016). The wealth index in Egypt is considered as the most important factor in the utilization of antenatal health care (Zaky et al., 2019).

To investigate those indications, this paper aimed to study the effect of poverty and residence, whether it was urban or rural, on the relationship between women's education and their reception of reproductive health care when women's empowerment acted as a mediator in that relationship.

Within that model, several effects of poverty and residence were found; some of which were direct and others were indirect. That fact highlighted the importance of this study since most of the studies carried out within this framework dealt with the direct effects within that model, such as the effect of both women's and husbands' education on empowerment and reproductive health care, as well as the effect of women's empowerment on reproductive health care. On the other hand, those studies lack examining the indirect effects of poverty and residence. They also did not investigate the role of empowerment as a mediator between education and women's reception of reproductive health care as well as comparing those effects along the wealth index levels and the environments, whether urban or rural, in which women lived. This role of empowerment contributes to identifying the most important factors which, when available, lead to achieving the highest levels of obtaining reproductive health care.

\section{Literature Review}

Many studies around the world have examined the factors that can have a significant impact on women's reception of reproductive health care in its three stages before, during, and after delivery. By reviewing that literature, it was noted that most of these studies deal with the direct effects of those factors on women receiving reproductive health care.

As for the effect of education on empowerment, studies have shown that women's empowerment is significantly related to the husbands' education levels (Alishah et al., 2019; Mainuddin, Begum, Rawal, Islam, \& Islam, 2015; Samari, 2019), whereas (Alishah et al., 2019; Nazier \& Ramadan, 2018) did not show a significant correlation between women's empowerment and their education levels, but it showed significance in (Samari, 2019).

Concerning the impact of education on reproductive health care, studies have shown that woman's reception of reproductive health care is greatly affected by the education levels of the wife and husband (Afulani, Sayi, \& Montagu, 2018; Ahmed et al., 2010; Akram, Hamid, \& Akram, 2019; Bello et al., 2019; Dapaah \& Nachinaab, 2019; Ikeako et al., 2006; Tawiah, 2011; Yaya, Bishwajit, \& Shah, 2016; Zaky et al., 2019).

With regard to the effect of empowerment or some of its indicators on women's reception of reproductive health care, (Akram et al., 2019; Bello et al., 2019; Kawaguchi et al., 2014; Nayebi, Dolatian, Hasanpoor, Ebadi, \& Akbarzadeh, 
2019; Sado, Spaho, \& R.Hotchkissc, 2014; Tiruneh, Chuang, \& Chuang, 2017; Zaky et al., 2019) have shown that women's reception of reproductive health care is affected by women's empowerment, while (Chiang et al., 2012) reached that women's participation in household decision-making had no significant association with the use of maternal health services.

With reference to the basic idea of the current study, which is concerned with the indirect effects of education, for the husband and the wife, on women's reception of reproductive health care through the role that empowerment plays as a mediator, in addition to conducting comparisons of those effects according to some of the variables. The literature has indicated the importance of those variables in influencing women's reception of reproductive health care, the most prominent of which was poverty, or wealth, and residence.

It was found that the literature lacked this type of studies with a focus on examining only the direct effects of education, poverty, and residence, as (Akram et al., 2019; Izugbara \& Ngilangwa, 2010; Rashad \& Sharaf, 2016; Tanya Nagahawatte \& Goldenberg, 2008; Tawiah, 2011; Yaya et al., 2016) dealt with the importance of the role that poverty and residence play in women's reception of reproductive health care.

\section{Methods}

\subsection{Study Design}

The study utilized the data from the 2014 Egypt Demographic and Health Survey (EDHS) results. The sample was selected in several stages. First, a total of 926 primary sampling units, 481 shiakhas/sub-district neighborhoods or towns and 445 villages, were chosen with a probability that was proportional to the size. Second, the units were divided into parts of roughly equal sizes, approximately 5000 inhabitants in each part. One to three parts were selected systematically from each unit, depending on the size of each shiakha/sub-district neighborhood, town, and village.

After that, a quick count was carried out on the selected parts in each unit, then two to three segments were selected from each unit. A household listing of families was obtained for each segment so as to select a systematic random sample of 29,471 household families. All women who were previously married, who aged between 15 - 49 years were eligible for the individual survey interview (Ministry of Health and Population, El-Zanaty Associates, \& I. C. F. International, 2015).

That survey was conducted on a sample of 21,762 married women, aged between 15 - 49 years across the Arab Republic of Egypt, excluding North and South Sinai governorates. The study sample was limited to currently married women who had previously given birth, had alive new-born children within the five years preceding the survey, and had only one marriage experience. All the women with missing data, whether in the variables that make up the empowerment index or the reproductive health care index, were excluded from the study, in addition to cases with outlier or extreme values. Thus, the sample size was 
reduced to 8427 women.

\subsection{Variables Description}

Moderator variables: There were two variables. The first was the wealth index that consisted of five categories: the very poor, the poor, the medium rich, the rich, and the very rich. The poor families were, then, separated and the variable was re-coded into two categories: the poor which included the very poor and the poor and the non-poor which included the medium rich, the rich, and the very rich. The second variable was residence, urban and rural.

Exogenous (Independent) variables: These independent variables were expressed in the number of years of the women's education (EDW) and the husbands' education (EDH).

Mediator variable: The women's empowerment index (EM) was structured using four main variables, each containing several sub-variables. The first main variable was "participation in decision making" which included three decisions: the health care for women, major household purchases, and visiting family or relatives. For each decision, if the woman was making the decision all by herself or in collaboration with the husband, she was given 1 and if she was not, she was given 0 . The second main variable was "women's control over the income" which included control over two types of income. The first was the husband's income. If the woman was in control over it all by herself or in collaboration with her husband, she was given 1 and if she was not, she was given 0 . The second type was the woman's income from her work, which she could make use of in case she ever got separated from her husband. She took 2 if she was in control over it all by herself or in collaboration with the husband, whereas she took 1 if the husband or others had the control over her income, and 0 for any other option. The third main variable was the "women's ownership of selected assets" which included two types of property: ownership of the residence and land ownership. The woman took 1 if she owned a property, residence or land, whereas she took 0 if she did not. The fourth and last main variable was "the extent to which the woman accepted domestic violence or her attitude towards husbands beating their wives'. That was examined through asking the woman whether the husband was justified in beating his wife in 5 types of practices: if she burned the food, went out without taking his permission, neglected the children, argued with him, and refused to have a sexual intercourse with him. For each practice, the woman took 1 if she did not accept beating by the husband, while she took 0 if she accepted it. The maximum limit of the empowerment index level was 13 whereas the minimum was 0 [0 - 13].

Endogenous (Dependent) variables: The Reproductive health care index (RC) was generated using ten variables: receiving medical antenatal care, the number of care visits during pregnancy, taking the tetanus vaccination, taking iron supplements during pregnancy, taking medication for intestinal worms during pregnancy, delivering in a place that provides medical care, receiving 
medical assistance at delivery, receiving medical postnatal care, taking Vitamin A supplements for 2 months after delivery, and the number of days to take a blood sample from the child's heel-within 14 days. The service provider included the doctor or the nurse/midwife, while the postnatal care included a postnatal check-up within the first two days after delivery regardless of where the delivery took place. The maximum limit of the reproductive health care index was 10 whereas the minimum was 0 [0 - 10].

\subsection{Data Analysis}

The study used some methods of data description in addition to using the Multiple-Group Path Analysis techniques. The aim was to evaluate the direct, indirect, and total effects among the variables of the study within the proposed model. Moreover, the study aimed to compare that model within each category of the wealth index and the residence referred to in the research.

\section{Results}

\subsection{Women's Proportional Distribution According to Some Variables}

Figure 1 shows the women's proportional distribution according to the degree of their empowerment and educational levels. The empowerment index scores 0 - 8 showed a decrease in the ratios for the line representing the "higher" level of education as compared to those representing lower levels of education. The line representing the "uneducated" level of education was the highest regarding most of the empowerment index scores during that period. However, the opposite was shown in the empowerment index scores 9 - 13 .

Figure 2 presents the women's proportional distribution according to the degree of their reproductive health care and educational levels. The reproductive health index scores 4 - 8 showed a decrease in the ratios for the line representing the "higher" level of education as compared to those representing lower levels of education. However, the opposite was shown in the reproductive health care index scores 9 - 12 .

Figure 3 reveals the women's educational levels according to the wealth index

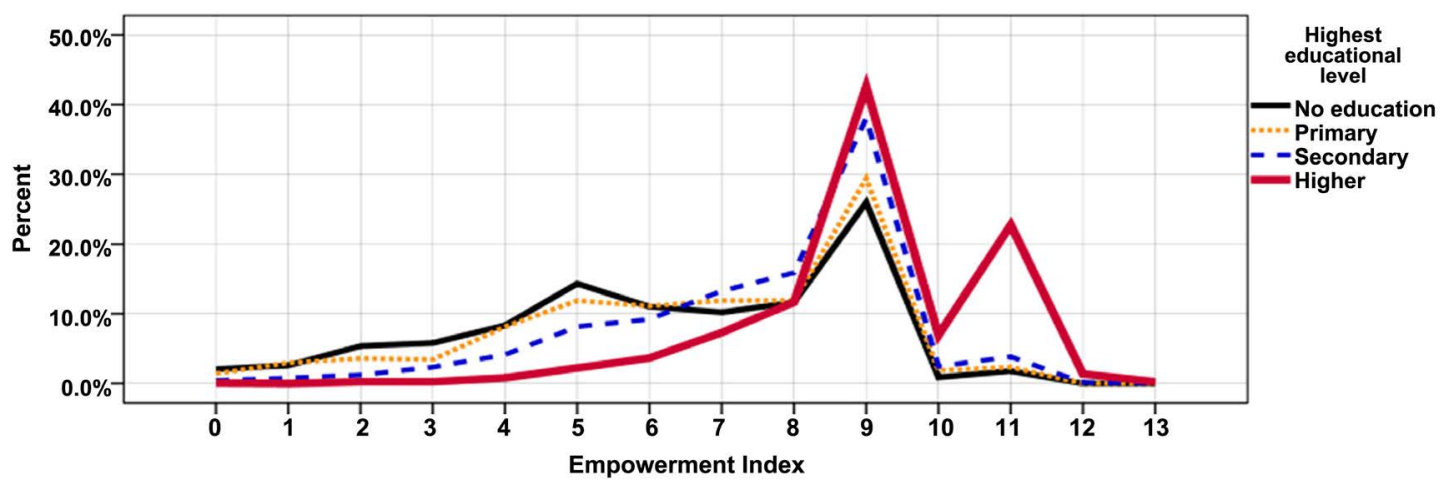

Figure 1. Women's proportional distribution according to their empowerment scores and educational levels. 


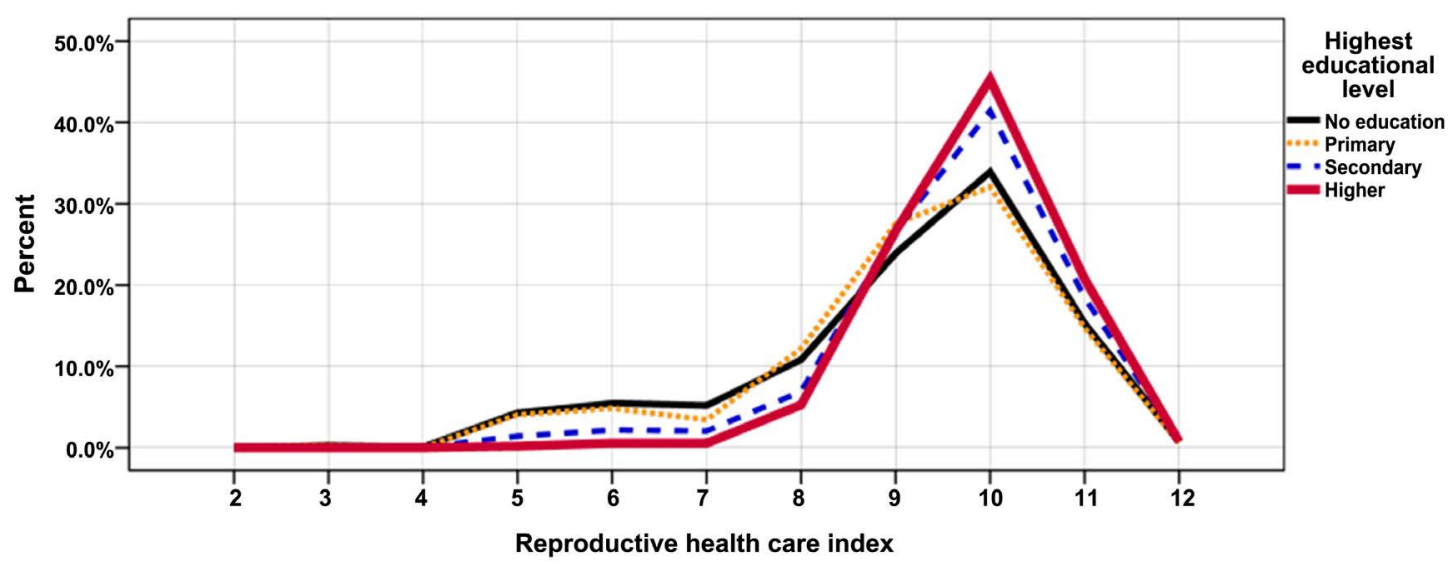

Figure 2. Women's proportional distribution according to their reproductive health care scores and educational levels.

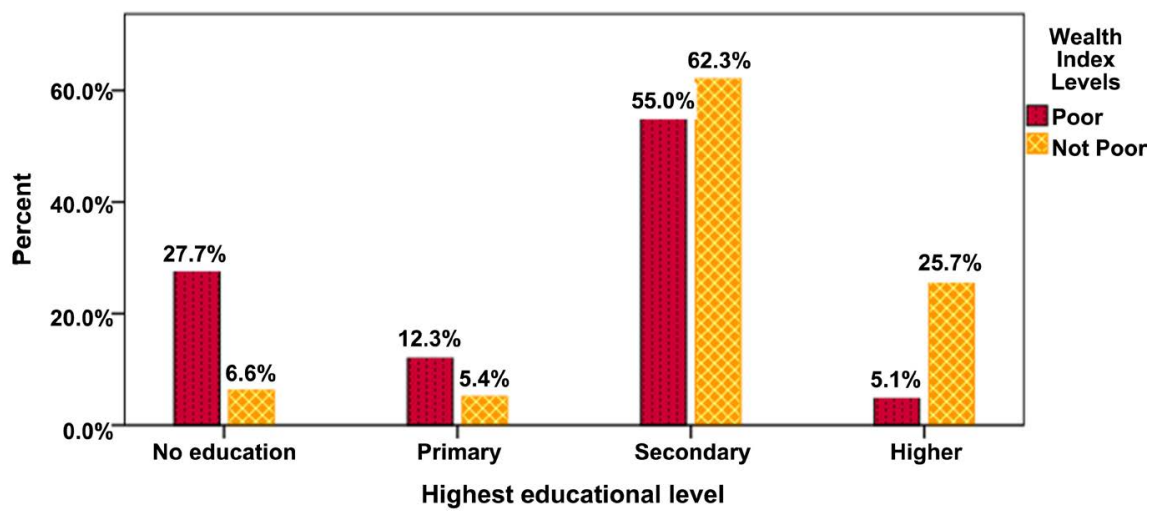

Figure 3. Women's highest educational levels according to the wealth index categories.

categories. It showed that the lowest percentage of the poor women who belonged to the "higher education" category, whereas the women, who were uneducated or who obtained only primary education, their percentages appeared higher than that of the non-poor women.

\subsection{The Proposed Model: Testing It for the Total Sample}

Figure 4 shows the final model for studying the role the empowerment played as a mediator between education and the women's reception of reproductive health care and the direct and indirect effects between these variables. The test of the saturated model for the total sample showed significance less than .001 for all the model paths except for the significance of the direct effect of the husbands" education on the reproductive health care, which appeared not significant.

As for the path model, it showed a good relevance to the data. Due to the large sample size, other parameters of the model quality were taken into consideration in addition to the $x^{2}$ value (Garson, 2013) $\left(x^{2}=.292, p=.589\right.$; RMSEA $=.000$; $\mathrm{CFI}=1.000$; GFI = 1.000; $\mathrm{AGFI}=1.000 ; \mathrm{NFI}=1.000$; $\mathrm{RFI}=1.000)$.

The tests of indirect effects showed that women's empowerment acted as a partial mediator between their education and their access to reproductive health 


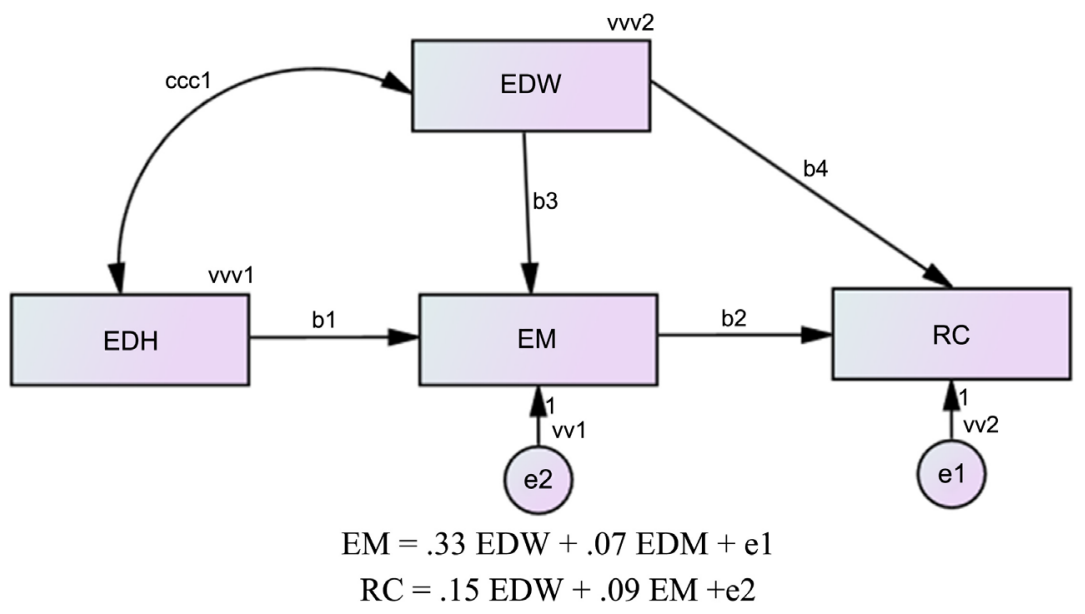

Figure 4. Path diagram for the effect of education on reproductive health care when the women's empowerment acted as a mediator.

care, while it acted as a full mediator between the husbands' education and women's access to reproductive health care.

The effects-standardized, unstandardized, direct, indirect, and total-are shown in Table 1 The women's education had the highest total effect on their reception of the reproductive health care (.177), followed by their empowerment (.086), then the husbands' education (.006). The women's education also had the greatest effect on their empowerment (.331) as compared to the husbands' education (.075).

\subsection{Multiple-Group Path Analysis}

\subsubsection{Wealth Index Model}

To examine and compare the effect of education and empowerment on reproductive health care for the poor and non-poor women, a multiple-group path analysis was used. The unconstrained path model showed a good relevance to the data $\left(x^{2}=1.574, p=.455\right.$; RMSEA $=.000$; CFI $=1.000$; GFI $=1.000$; AGFI $=.999 ; \mathrm{NFI}=1.000 ; \mathrm{RFI}=.998$ ).

The effects of all model paths showed significance less than .001 for both groups, except for the significance of the path between the husbands' education (EDH) and empowerment (EM) for the poor group since it showed less than .05. Table 2 presents the direct, indirect, and total unstandardized effects of the two groups under study, in addition to the results of the Z-test.

The values indicated that the direct effect of a husband's education on women's empowerment among the non-poor women (.036) was much higher, nearly twice, than its effect among the poor women (.022). On the contrary, the direct effect of the women's empowerment on receiving reproductive health care among the poor women (.058) was much higher than its effect among the non-poor women (.034). In addition, the direct, indirect, and total effect of the women's education on receiving reproductive health care was higher among the poor women than the non-poor women, while that effect on empowerment among the poor women was lower than the non-poor women. 
Table 1. The total sample regression estimate results of the final path model.

\begin{tabular}{lccccccccccc}
\hline & \multicolumn{4}{c}{ Unstandardized Regression Weights } & \multicolumn{4}{c}{$\begin{array}{c}\text { Standardized } \\
\text { Regression Weights }\end{array}$} \\
\cline { 2 - 10 } & $\begin{array}{c}\text { Estimate } \\
\text { (D.E.) }\end{array}$ & S.E. & C.R. & $P$ & I.E. & T.E. & D.E. & I.E. & T.E. \\
\hline EM <--- EDH & .036 & .006 & 6.142 & $* * *$ & .000 & .036 & .075 & .000 & .075 \\
EM <--- EDW & .156 & .006 & 27.079 & $* * *$ & .000 & .156 & .331 & .000 & .331 \\
RC <--- EM & .049 & .007 & 7.429 & $* * *$ & .000 & .049 & .086 & .000 & .086 \\
RC <--- EDW & .040 & .003 & 12.938 & $* * *$ & .008 & .048 & .149 & .028 & .177 \\
RC <--- EDH & & & & & .002 & .002 & .000 & .006 & .006 \\
\hline$* *$ significantly different from zero at the .001 level (two-tailed); D.E. = Direct Effect; I.E. = Indirect Effect; \\
T.E. = Total Effect.
\end{tabular}

Table 2. Differences in path coefficients between the poor and the non-poor women.

\begin{tabular}{|c|c|c|c|c|c|c|c|c|c|c|c|c|c|}
\hline \multirow{3}{*}{ Path } & \multicolumn{6}{|c|}{ Poor } & \multicolumn{6}{|c|}{ Not Poor } & \multirow{3}{*}{ Z-score } \\
\hline & \multicolumn{6}{|c|}{ Unstandardized Regression Weights } & \multicolumn{6}{|c|}{ Unstandardized Regression Weights } & \\
\hline & $\begin{array}{c}\text { Estimate } \\
\text { (D.E.) }\end{array}$ & S.E. & C.R. & $\mathbf{P}$ & I.E. & T.E. & $\begin{array}{c}\text { Estimate } \\
\text { (D.E.) }\end{array}$ & S.E. & C.R. & $\mathbf{P}$ & I.E. & T.E. & \\
\hline $\mathrm{EM}<---\mathrm{EDH}$ & .022 & .011 & 1.982 & .048 & .000 & .022 & .036 & .007 & 5.513 & $* * *$ & .000 & .036 & 1.132 \\
\hline EM <--- EDW & .113 & .011 & 10.569 & $* * *$ & .000 & .113 & .126 & .007 & 692 & $* * *$ & .000 & .126 & .995 \\
\hline $\mathrm{RC}<---\mathrm{EM}$ & .058 & .012 & 5.012 & $* * *$ & .000 & .058 & .034 & .008 & 4.109 & $* * *$ & .000 & .034 & -1.732 \\
\hline RC <--- EDW & .045 & .006 & 7.775 & $* * *$ & .007 & .052 & .031 & .004 & 8.029 & $* * *$ & .004 & .036 & $-2.007^{* *}$ \\
\hline RC <--- EDH & & & & & .001 & .001 & & & & & .001 & .001 & \\
\hline
\end{tabular}

${ }^{* * *}$ significantly different from zero at the .001 level (two-tailed); ${ }^{* *} P$ value $<.05$; D.E. $=$ Direct Effect; I.E. $=$ Indirect Effect; T.E. $=$ Total Effect.

Table 2 also shows the values for comparing the coefficients of the model paths, which were the values of the Z-test for the difference between the coefficients from model 1 (the poor women) and model 2 (the non-poor women). The path coefficient for the effect of the women's education on receiving reproductive health care was the only one that differed significantly between the poor and non-poor women. By comparing the Z-test value (-2.007) with the absolute value |1.96|, it was found that it exceeded that critical value at the level of $p<.05$ (Denis, 2010).

On the other hand, it was found that the rest of the $\mathrm{Z}$ values were smaller than the critical value |1.96|, which meant that the difference between those paths was not statistically significant at $p<.05$.

Constraining the structural parameters of the mediation model showed a significant decline in the model relevance $\left(x^{2}=15.646, \mathrm{df}=6, p=.016\right)$.

When making improvements to the model by removing some constraints, those improvements resulted in three models. The elimination of the residual variance constraints - of the reproductive health care, women's education variance, and the direct effect of women's education on the reproductive health care-resulted in the insignificance of $x^{2}\left(x^{2}=9.092, \mathrm{df}=5, p=.105\right)$. 
Therefore, in conclusion, the direct effects of the model did not differ with regards to the groups, except for the direct effect of women's education on the reproductive health care (Garson, 2013).

For a comparison of the size of the path effect within each of the wealth groups, Table 3 presents the direct, indirect, and total standardized effects of these groups. It was found that among the non-poor women, the effect of empowerment on receiving reproductive health care was approximately $50 \%$ less than the effect of their education on receiving this type of care. On the other hand, among the poor women, that percentage increased to approximately $65 \%$.

As for women's empowerment, it was found that it was affected by women's education five times more than by their husbands' education, among the poor women, and three times more than by their husbands' education among the non-poor women.

\subsubsection{Residence Model}

The mediation model, which was unrestricting to education, empowerment, and reproductive health care of the urban and rural women, showed adequate relevance of the data $\left(x^{2}=5.198, p=.074\right.$; RMSEA $=.014$; CFI $=.999$; GFI $=1.000$; $\mathrm{AGFI}=.997$; NFI $=.999 ; \mathrm{RFI}=.993$ ).

All the model paths revealed less than .001 significance for both groups. Table 4 presents the direct, indirect and total unstandardized effects of the two groups under study, in addition to the results of the Z-test.

Table 3. Standardized regression weights for the poor and the non-poor women.

\begin{tabular}{ccccccc}
\hline \multirow{2}{*}{ Path } & \multicolumn{3}{c}{ Poor } & \multicolumn{3}{c}{ Non-Poor } \\
\cline { 2 - 7 } & D.E. & I.E. & T.E. & D.E. & I.E. & T.E. \\
\hline EM <--- EDH & .042 & .000 & .042 & .083 & .000 & .083 \\
EM <--- EDW & .042 & .000 & .226 & .265 & .000 & .265 \\
RC <--- EM & .098 & .000 & .098 & .056 & .000 & .056 \\
RC <--- EDW & .000 & .004 & .004 & .000 & .005 & .005 \\
RC <--- EDH & .152 & .022 & .174 & .110 & .015 & .125 \\
\hline
\end{tabular}

D.E. $=$ Direct Effect; I.E. $=$ Indirect Effect; T.E. $=$ Total Effect.

Table 4. Differences in path coefficients between the urban and the rural women.

\begin{tabular}{|c|c|c|c|c|c|c|c|c|c|c|c|c|c|}
\hline \multirow{3}{*}{ Path } & \multicolumn{6}{|c|}{ Urban } & \multicolumn{6}{|c|}{ Rural } & \multirow{3}{*}{ Z-score } \\
\hline & \multicolumn{6}{|c|}{ Unstandardized Regression Weights } & \multicolumn{6}{|c|}{ Unstandardized Regression Weights } & \\
\hline & $\begin{array}{c}\text { Estimate } \\
\text { (D.E.) }\end{array}$ & S.E. & C.R. & $\mathbf{P}$ & I.E. & T.E. & $\begin{array}{c}\text { Estimate } \\
\text { (D.E.) }\end{array}$ & S.E. & C.R. & $\mathbf{P}$ & I.E. & T.E. & \\
\hline EM <--- EDH & .043 & .008 & 5.407 & $* * *$ & .000 & .043 & .027 & .008 & 3.306 & $* * *$ & .000 & .027 & -1.368 \\
\hline EM <--- EDW & .137 & .008 & 16.255 & $* * *$ & .000 & .137 & .145 & .008 & 18.337 & $* * *$ & .000 & .145 & .679 \\
\hline RC $<---$ EM & .047 & .011 & 4.362 & $* * *$ & .000 & .047 & .061 & .008 & 7.242 & $* * *$ & .000 & .061 & 1.002 \\
\hline RC <--- EDW & .042 & .005 & 652 & $* * *$ & .006 & .049 & .045 & .004 & 10.994 & $* * *$ & .009 & .054 & .398 \\
\hline RC <--- EDH & & & & & .002 & .002 & & & & & .002 & .002 & \\
\hline
\end{tabular}

${ }^{* * *}$ significantly different from zero at the .001 level (two-tailed); D.E. = Direct Effect; I.E. = Indirect Effect; T.E. = Total Effect. 
The values indicated that the direct effect of a husband's education on women's empowerment among the urban women (.043) was much higher than that among the rural women (.027). On the contrary, the direct effect of women's empowerment on receiving reproductive health care among the rural women (.61) was much higher than that among the urban women (.047). There was also a slight increase in the direct, indirect, and total effect of women's education on receiving reproductive health care among the rural women as compared to the urban women, while the effect on empowerment among the urban women was less than that among the rural women.

Table 4 also displays the values for comparing the coefficients of the model paths, which were the Z-test values for the difference between the coefficients from model 1 (the urban women) and model 2 (the rural women). By comparing all Z-test values to the absolute value |1.96|, the result was that they did not exceed that critical value, which meant that the difference between these paths was not statistically significant at $p<.05$.

Constraining the structural parameters of the mediation model resulted in a significant decline in the model relevance $\left(x^{2}=8.713\right.$, $\left.\mathrm{df}=6, p=.190\right)$. That is, there were no differences between the urban and rural women in the effects of the direct paths of the model.

For a comparison of the size of the path effect within each of the residence groups, Table 5 presents the direct, indirect, and total standardized effects of the residence groups. It was found that among the urban women, the effect of women's empowerment on receiving reproductive health care was approximately $50 \%$ less than the effect of their education on receiving this type of care. On the other hand, among the rural women, that percentage increased to approximately $66 \%$.

As for women's empowerment, it was found that it was affected by women's education five times more than by their husbands' education among rural women, and up to three times more than by their husbands' education among the urban women.

\section{Discussion}

Given that there are several effects in the model under study, such as the effect of

Table 5. Standardized regression weights for the urban and rural women.

\begin{tabular}{ccccccc}
\hline \multirow{2}{*}{ Path } & \multicolumn{3}{c}{ Urban } & \multicolumn{3}{c}{ Rural } \\
\cline { 2 - 7 } & D.E. & I.E. & T.E. & D.E. & I.E. & T.E. \\
\hline EM <--- EDH & .101 & .000 & .101 & .054 & .000 & .054 \\
EM <--- EDW & .303 & .000 & .303 & .298 & .000 & .298 \\
RC <--- EM & .075 & .000 & .075 & .109 & .000 & .109 \\
RC <--- EDW & .000 & .008 & .008 & .000 & .006 & .006 \\
RC <--- EDH & .149 & .023 & .172 & .165 & .032 & .198 \\
\hline
\end{tabular}

D.E. = Direct Effect; I.E. = Indirect Effect; T.E. = Total Effect. 
education for both the husband and the wife on empowerment, the effect of empowerment on reproductive health care, and the effect of education on care, each effect will be discussed separately from two angles; first, the significance of the direct and indirect path effect, and second, the role of moderator variables (poverty and residence) on this effect.

\subsection{Empowerment and Education}

The results of the study, for the total sample, urban, rural, poor, and non-poor women, show that women's empowerment is positively and strongly affected by their education and their husbands' education. Therefore, women got a greater score on the empowerment index whenever their educational level as well as their husbands' were higher. Women's empowerment was affected by their education much more greater than their husband's education.

This result is in agreement with that in (Samari, 2019) as his study was on Egypt. Both agreed in that the women, who had a high level of education as well as their husbands, made more decisions within their families. The result of this study is also in concordance with (Aly, 2000) as her study was on Egypt as well. Both agreed in that the wife's education level, followed by the husband's, came in the first and second place respectively in terms of the degree of correlation with the level of the woman's status in the family.

Mainuddin et al. (2015), in a study on Bangladesh, found that women's empowerment correlated with their husbands' education levels. That result differs from (Nazier \& Ramadan, 2018), in his study on Egyptian women, in that all education categories, as compared to the illiterate category, did not have a significant effect on empowerment in its two dimensions, decisions and mobility. He described that result as surprising and referred it to the education system in Egypt, which could not change the intellectual system of its community members to achieve gender equality.

The present study reveals results about the role of poverty and residence and their effect on women's empowerment. Those results show that there are no significant differences, between the poor and the non-poor women as well as between the rural and the urban women, in terms of the effect of education on empowerment, whether it is the wife's or the husband's education. The results also show that women's empowerment is affected by their education five times more than by their husband's education among the poor and the rural women, and up to three times more than by their husband's education among the nonpoor and the urban women.

The rural areas are those of concentration of the poor people in Egypt (Nazier \& Ramadan, 2018). This justifies what the study results show: the similarity of the effect of the husband's education on empowerment among both the rural and the poor women. That effect among the non-poor (.036) and the urban women (.043), approaches twice its effect among the poor (.022) and the rural women (.027). It is noticed that poverty and residence in the rural areas weaken the effect of the husband's education on women's empowerment, which could be 
the result of the patriarchal culture that is still prevalent to some extent in the rural societies and which most rural men do not abandon even if they reach the highest levels of education.

\subsection{Women's Education and Reproductive Health Care}

It is assumed that an educated woman is more aware of the importance of medical follow-ups throughout the pregnancy period and during and after delivery, not only for her own health, but for the health of her foetus as well. Education enables women to understand the medical instructions more clearly, to get acquainted with everything new in this respect, and to know the dimensions of neglecting any aspect of pregnancy care and delivery, which may lead to the death of a high percentage of mothers and foetuses in various countries around the world.

This is what the study results show in terms of a strong positive significance $(P<.001)$ for the effect of the direct path between women's education and receiving reproductive health care. Women's education has the highest total effect on their reception of reproductive health care.

This result is in agreement with that in (Chiang et al., 2012) about a study conducted on rural Egypt, and that in (Akram et al., 2019) about a study conducted in Pakistan. They all agreed that women's higher education levels had positive significant correlations with the three dimensions of the medical services for maternal health, before, during, and after delivery.

According to (Ahmed et al., 2010), in his study conducted on the developing countries, he concluded that the women who completed their primary education were three times more likely to make at least four antenatal care visits and five times more likely to have a skilled midwife during their delivery.

Likewise (Bello et al., 2019), in their study conducted on Western Kenya, they reached the conclusion that the educational level that was higher than the primary level correlated with the increase in attending more than one antenatal care visit as compared to the level of primary education or lower.

With reference to (Yaya et al., 2016), in his study conducted on Malawi, he showed that the rates of using maternity health care services were greatly affected by the differences in education.

Moreover, (Afulani et al., 2018) found that the women, who could write well, scored about five points higher on the Person-Centred Maternity Care (PCMC) scale than those who could not.

As for the role of poverty and residence on the effect of women's education on receiving reproductive health care, the results of the present study show that there are significant differences between the poor and the non-poor women in terms of the direct effect of women's education on receiving reproductive health care. The direct, indirect, and total effect among the poor women is higher than on the non-poor. On the other hand, there are no significant differences between the urban and the rural women as the direct and total effect among the rural women is slightly higher than the urban women. 
This indicates that education plays a good role in the lives of the poor women and makes them in a better position in terms of their access to reproductive health care as compared to the non-poor women. This can be explained by the fact that money plays the main role among the category of the non-poor women since the woman who lives in a good financial position can seek to receive the required care, not because she is aware of the importance of this reception as much as she feels the obligation to obtain it as long as she can pay the fees for it. On the other hand, education plays the main role among the poor women category. Despite being poor, these women's awareness of the importance of receiving this type of care, which increases with the increase of their education, makes them seek to obtain it.

\subsection{Husbands' Education and Reproductive Health Care}

The results of the study show that the effect of the direct path between the husbands' education and the women's reception of reproductive health care is not significant, and that the indirect effect is significant only through empowerment as a mediator. This comes as a result of the fact that the Egyptian man, whether he is educated or uneducated, is often busy with his work, leaving the pregnancy and delivery processes to his wife to manage them according to what she thinks as appropriate for her in this regard. The details of that process are not among the priorities of the husband's thinking. Therefore, his education has no direct effect on his wife's reception of reproductive health care, whereas the indirect effect is significant through empowerment as a mediator. This is because the Egyptian man usually leaves the burden of managing family life to his wife. Moreover, the degree of the authorization he grants to his wife depends on the level of his education, awareness, and the culture of his environment and origin.

\subsection{Empowerment and Reproductive Health Care}

The results of the study show a highly positive significance for the effect of women's empowerment on receiving reproductive health care.

This result is in agreement with that in (Sado et al., 2014), about his study conducted on Albania, in that women's empowerment within the family affected their use of maternal health care services. In addition, the result agrees also with (Akram et al., 2019) in a study conducted on Pakistan and with (Tiruneh et al., 2017) in a study conducted on Ethiopia. They all agreed that empowering women had a positive significant effect on benefiting from the maternal health care service facilities in the three stages. As for (Ahmed et al., 2010), in his study about developing countries, he concluded that the inequalities in women's empowerment in 31 countries were related to the decrease in the use of maternal health services, and that women with the highest empowerment score were more likely to attend four or more antenatal care visits and had a skilled midwife during their delivery.

(Kawaguchi et al., 2014) in a study conducted on a village in Giza, Egypt, in- 
dicated that empowerment was measured using five dimensions: freedom of movement, economic security and stability, family support and freedom from domination, decision-making in daily life, and society participation. It was found that family support and freedom from domination was the only factor among these dimensions that was positively associated with the use of maternal health services.

On the other hand, (Bello et al., 2019) in a study conducted on Western Kenya, found that women's empowerment was not associated with early antenatal care (ANC) use. As for (Chiang et al., 2012), in a study conducted on the rural areas of Egypt, also found that participation in household decision-making was not significantly associated with maternal health services use.

The results of the current study also conclude that there are no significant differences between the poor and the non-poor women, as well as between the rural and the urban women, with regard to the effect of empowerment on women's reception of reproductive health care. However, the effect of empowerment on receiving reproductive health care among the poor women is much higher than among the non-poor women, and it is also very high among the rural women as compared to the urban women. This can be explained by the fact that, as mentioned previously, poverty in the Egyptian society is mostly concentrated in the rural areas, therefore, the effect among the poor women, who mostly live in the rural areas, is higher than among the non-poor women who live in the urban areas. This is because the women in the rural areas are surrounded by the patriarchal culture. Nevertheless, those women, whose circumstances help them to gain a high status in their families that enables them to have a role in decision-making and refuse any humiliating treatment from their husbands, are more able to receive this type of health care.

On the other hand, the results of the study show that the effect of women's education on receiving reproductive health care is much higher than the effect of their empowerment. Therefore, the effect of empowering women reached nearly $50 \%$ of the effect of the education among the non-poor and the urban women. This can be explained by the fact that these women may have a high status in their families, but they do not have the sufficient awareness of the importance of obtaining reproductive health care services, while the educated women mostly have this awareness even if they do not have the required level of empowerment.

\section{Conclusion}

The impact of both women's education and empowerment on receiving reproductive health care is the highest among the poor and the rural dwellers, while the effect of a husband's education on empowerment is weak among these categories. Accordingly, it is recommended to:

- Reduce female illiteracy and dropping out of the different educational levels among the poor by providing them with educational opportunities through the government without financial burdens while giving their families some 
benefits to encourage learning among these categories.

- Create a new societal culture through the Ministry of Education and the Ministry of Higher Education by reforming the educational curricula, in a way that enables them to have a role in teaching the method that should be followed in bringing up the new generations away from the gender discrimination that is most severe in the rural areas.

- Mitigate poverty through the Enterprise Development Authority in the country by preparing small projects in various disciplines that can be immediately delivered or implemented with full support in terms of training, marketing and financial facilities, and promoting this through a large advertising campaign.

\section{Conflicts of Interest}

The author declares no conflicts of interest regarding the publication of this paper.

\section{References}

Abbas, A., Amin, M., Ali, S., \& Salem, N. (2016). Maternal Mortality: A Tertiary Care Hospital Experience in Upper Egypt. International Journal of Reproduction, Contraception, Obstetrics and Gynecology, 5, 1466-1471. https://doi.org/10.18203/2320-1770.ijrcog20161306

Activities, U. N. F. f. P. (2011). Follow-Up Actions to the Recommendations of the International Conference on Population and Development (Fertility, Reproductive Health and Development). Report of the Secretary-General United Nations E/CN.9/2011/1.

Activities, U. N. F. f. P. (2014). Framework of Actions for the Follow-Up to the Programme of Action of the International Conference on Population and Development Beyond 2014. Report of the Secretary-General United Nations A/69/62.

Afulani, P. A., Sayi, T. S., \& Montagu, D. (2018). Predictors of Person-Centered Maternity Care: The Role of Socioeconomic Status, Empowerment, and Facility Type. BMC Health Services Research, 18, 360. https://doi.org/10.1186/s12913-018-3183-x https://www.ncbi.nlm.nih.gov/pmc/articles/PMC5948900

Ahmed, S., Creanga, A. A., Gillespie, D. G., \& Tsui, A. O. (2010). Economic Status, Education and Empowerment: Implications for Maternal Health Service Utilization in Developing Countries. PLoS ONE, 5, e11190.

https://doi.org/10.1371/journal.pone.0011190

https://journals.plos.org/plosone/article?id=10.1371/journal.pone.0011190

Akram, N., Hamid, A., \& Akram, M. I. (2019). Role of Women Empowerment in Utilization of Maternal Healthcare Services: Evidence from Pakistan. Pakistan Economic and Social Review, 57, 93.

https://www.researchgate.net/publication/336363953 ROLE OF WOMEN EMPOWE RMENT IN UTILIZATION OF MATERNAL HEALTHCARE SERVICES EVIDE NCE FROM PAKISTAN

Alishah, A., Ganji, J., Mohammadpour, R., Kiani, Z., \& Shahhosseini, Z. (2019). Women's Reproductive Empowerment: A Comparative Study of Urban and Rural Females in Iran. International Journal of Women's Health and Reproduction Sciences, 7, 294-300. https://doi.org/10.15296/ijwhr.2019.49

Aly, R. M. (2000). Women Status in the Egyptian Family and Some of Its Correlates. 
Master Thesis, Cairo: Cairo University, Faculty of Graduate Studies for Statistical Research.

Bello, F. O., Musoke, P., Kwena, Z., Owino, G. O., Bukusi, E. A., Darbes, L., \& Turan, J. M. (2019). The Role of Women's Empowerment and Male Engagement in Pregnancy Healthcare Seeking Behaviors in Western Kenya. Women \& Health, 59, 892-906. https://doi.org/10.1080/03630242.2019.1567644

CAPMAS (2020). Egypt in Figures 2020. Capmas.gov.eg.

Chiang, C., Elshair, I. H. H., Kawaguchi, L., Fouad, N. A. M., Abdou, N. M., Higuchi, M., Aoyama, A. et al. (2012). Improvements in the Status of Women and Increased Use of Maternal Health Services in Rural Egypt. Nagoya Journal of Medical Science, 74, 233-240. https://www.ncbi.nlm.nih.gov/pmc/articles/PMC4831232

Dapaah, J. M., \& Nachinaab, J. O. (2019). Sociocultural Determinants of the Utilization of Maternal Health Care Services in the Tallensi District in the Upper East Region of Ghana. Advances in Public Health, 2019, Article ID: 5487293.

https://www.hindawi.com/journals/aph/2019/5487293 https://doi.org/10.1155/2019/5487293

Denis, D. (2010). Multi-Group Analysis in AMOS (with Pairwise Tests of Path Coefficients). Missoula, MT: University of Montana.

El Feki, S., Heilman, B., \& Barker, G. (2017). Understanding Masculinities: Results from the International Men and Gender Equality Survey (IMAGES)_Middle East and North Africa. New York: UN Women.

Garson, G. D. (2013). Path Analysis. Asheboro, NC: Statistical Associates Publishing.

Group, O. B. (2020). How Will Egypt Reform Its Education System? https://oxfordbusinessgroup.com/overview/forging-ahead-new-reforms-investment-an d-initiatives-are-aimed-fixing-ongoing-problems-and

Ikeako, L. C., Onah, H. E., \& Iloabachie, G. C. (2006). Influence of Formal Maternal Education on the Use of Maternity Services in Enugu, Nigeria. Journal of Obstetrics and Gynaecology, 26, 30-34. https://doi.org/10.1080/01443610500364004

Izugbara, C. O., \& Ngilangwa, D. P. (2010). Women, Poverty and Adverse Maternal Outcomes in Nairobi, Kenya. BMC Women's Health, 10, Article No. 33. https://bmcwomenshealth.biomedcentral.com/articles/10.1186/1472-6874-10-33 https://doi.org/10.1186/1472-6874-10-33

Kawaguchi, L., Fouad, N. A. M., Chiang, C., Elshair, I. H. H., Abdou, N. M., El Banna, S. R., \& Aoyama, A. (2014). Dimensions of Women's Empowerment and Their Influence on the Utilization of Maternal Health Services in an Egyptian Village: A Multivariate Analysis. Nagoya Journal of Medical Science, 76, 161-171. https://www.ncbi.nlm.nih.gov/pmc/articles/PMC4345726

Kiani, Z., Simbar, M., Dolatian, M., \& Zayeri, F. (2018). Women's Empowerment in Reproductive Decision-Making Needs Attention among Iranian Women. Iranian Journal of Public Health, 47, 464-465. https://www.ncbi.nlm.nih.gov/pmc/articles/PMC5971191

Mainuddin, A., Begum, H. A., Rawal, L. B., Islam, A., \& Islam, S. S. (2015). Women Empowerment and Its Relation with Health Seeking Behavior in Bangladesh. Journal of Family \& Reproductive Health, 9, 65-73. https://pubmed.ncbi.nlm.nih.gov/26175761

Ministry of Planning, M. a. A. R. (2018). Vision of Egypt 2030. Egypt's Voluntary National Review (p. 8).

Ministry of Health and Population, El-Zanaty Associates, \& I. C. F. International, (2015). Egypt Demographic and Health Survey 2014. Cairo: Ministry of Health and Population 
and ICF International.

Nayebi, N. A. S., Dolatian, M., Hasanpoor, A. S. B., Ebadi, A., \& Akbarzadeh, B. A. (2019). Exploring the Reproductive Health Needs of Violent Women: A Qualitative Study. http://ijwhr.net/pdf/pdf IJWHR 343.pdf

Nazier, H., \& Ramadan, R. (2018). What Empowers Egyptian Women: Resources versus Social Constrains? Review of Economics and Political Science, 3, 153-175. https://doi.org/10.1108/REPS-10-2018-015 https://www.emerald.com/insight/content/doi/10.1108/REPS-10-2018-015/full/html

Ragab, A., Girgis, H., Zaki, H., Osman, M., Al-Khorazaty, N., \& Hamed, R. (2016). Population Situation Analysis Egypt 2016. Bassera, UNFPA and NPC, 59, 105 \& 112. https://egypt.un.org/en/17376-population-situation-analysis-egypt-2016

Rashad, A. S., \& Sharaf, M. F. (2016). Socio-Economic Inequalities in Maternity Care under Political Instability: Evidence from Egypt, Jordan and Yemen. Paper Presented at the Economic Research Forum Working Paper Series.

Roach, E. (2019). Education in Egypt. https://wenr.wes.org/2019/02/education-in-egypt-2

Sado, L., Spaho, A., \& R.Hotchkissc, D. (2014). The Influence of Women's Empowerment on Maternal Health Care Utilization: Evidence from Albania. Social Science \& Medicine, 114, 169-177. https://doi.org/10.1016/j.socscimed.2014.05.047 https://www.sciencedirect.com/science/article/abs/pii/S0277953614003414

Samari, G. (2019). Women's Empowerment in Egypt: The Reliability of a Complex Construct. Sexual and Reproductive Health Matters, 27, Article ID: 1586816. https://www.ncbi.nlm.nih.gov/pmc/articles/PMC6753836 https://doi.org/10.1080/26410397.2019.1586816

Shawky, S., Rashad, H., \& Khadr, Z. (2018). Reproductive Health Inequalities in Egypt. Evidence for Guiding Policies, Final Report: UNFPA/ASRO.

Tanya Nagahawatte, N., \& Goldenberg, R. L. (2008). Poverty, Maternal Health, and Adverse Pregnancy Outcomes. Annals of the New York Academy of Sciences, 1136, 80-85. https://doi.org/10.1196/annals.1425.016

Tawiah, E. O. (2011). Maternal Health Care in Five Sub-Saharan African Countries. African Population Studies, 25, 1. https://aps.journals.ac.za/pub/article/view/264

Tiruneh, F. N., Chuang, K.-Y., \& Chuang, Y.-C. (2017). Women's Autonomy and Maternal Healthcare Service Utilization in Ethiopia. BMC Health Services Research, 17, 718. https://doi.org/10.1186/s12913-017-2670-9

UNWomen (2020). The World for Women and Girls: Annual Report 2019-2020.

WEF (2020). Global Gender Gap Report 2020 (p. 30).

Yaya, S., Bishwajit, G., \& Shah, V. (2016). Wealth, Education and Urban-Rural Inequality and Maternal Healthcare Service Usage in Malawi. BMJ Global Health, 1, e000085. http://gh.bmj.com/content/1/2/e000085.abstract https://doi.org/10.1136/bmjgh-2016-000085

Zahran, K. M., Fadel, K. A.-M., Ahmed, S. M., \& El-Gazzar, A. F. (2017). Maternal Mortality in an Academic Institution in Upper Egypt. Journal of Obstetrics and Gynaecology, 37, 315-319. https://doi.org/10.1080/01443615.2016.1242559

Zaky, H. H. M., Armanious, D. M., \& Hussein, M. A. (2019). Determinants of Antenatal Health Care Utilization in Egypt (2000-2014) Using Binary and Count Outcomes. Health, 11, 25-39. https://doi.org/10.4236/health.2019.111004

https://www.scirp.org/journal/paperinformation.aspx?paperid $=89827$ 